Supporting Information for:

The Influence of Mechanical Ventilation Systems and Human Occupancy on Time-Resolved Source Rates of Volatile Skin Oil Ozonolysis Products in a LEED-Certified Office Building

Tianren $\mathrm{Wu}^{1,2}$, Antonios Tasoglou ${ }^{3}$, Heinz Huber ${ }^{4}$, Philip S. Stevens ${ }^{5,6}$, and Brandon E. Boor ${ }^{1,2^{*}}$

${ }^{1}$ Lyles School of Civil Engineering, Purdue University, West Lafayette, Indiana 47907, U.S.

${ }^{2}$ Ray W. Herrick Laboratories, Center for High Performance Buildings, Purdue University, West Lafayette, Indiana 47907, U.S.

${ }^{3}$ RJ Lee Group Inc., Monroeville, Pennsylvania 15146, U.S.

${ }^{4}$ Edelweiss Technology Solutions, LLC, Novelty, Ohio 44072, U.S.

${ }^{5} \mathrm{O}$ 'Neill School of Public and Environmental Affairs, Indiana University, Bloomington, Indiana 47405, U.S.

${ }^{6}$ Department of Chemistry, Indiana University, Bloomington, Indiana 47405, U.S.

*Corresponding author: e-mail: bboor@purdue.edu

Number of Pages: 23

Number of Figures: 10

Number of Tables: 4

\title{
Table of Contents
}

Detailed Description of the Herrick Living Laboratories at Purdue University: pg. S2-S3

Detailed Description of the PTR-TOF-MS Measurements: pg. S3

Additional Measurements: pg. S3-S4

Automated Valve System for Multi-Location Sampling Across Living Laboratory HVAC System: pg. S4

Data Analysis: pg. S5

Figures (S1-S10): pg. S6-S16

Tables (S1-S4): pg. S17-S22

References: pg. S23 
Detailed Description of the Herrick Living Laboratories at Purdue University

The Herrick Living Laboratories (LL) at Purdue University are four modern open-plan offices with modular and reconfigurable lighting, air distribution, radiant, and building envelope systems. They are located within the Ray W. Herrick Laboratories (40²5'19.4"N 8655'11.6"W), which is a high-performance building awarded a LEED Gold Certificate in 2013. ${ }^{1}$ They were designed for research on building system design and operation, energy use, indoor environmental quality, and occupant comfort within a realistic context. ${ }^{2}$ Each office has its own precisely controlled HVAC system and air handling unit (AHU). Control is enabled by Tridium JACE controllers and the Niagara/AX software framework (Tridium Inc., Richmond, VA, U.S.A.). This building management system allows us to monitor, control, and automate LL building parameters via an internet-based platform.

The four LL offices are identical in geometry, and each has a south-facing, full-size double glass façade. Automated shading is used along the façade to block sunlight, and its height varies with the time of the day. Each office has 20 workstations with assigned graduate students. Each workstation includes an armchair, a desk, and two under-table cabinets. The measurement campaign was conducted in one of the LL offices, where the air is supplied through floor diffusers that are evenly distributed throughout the room. The LL office has hard tile flooring, painted walls, and ceiling tiles. The dimensions are $10.5 \mathrm{~m} \times 9.9 \mathrm{~m} \times 3.2 \mathrm{~m}(\mathrm{~L} \times \mathrm{W} \times \mathrm{H})$. Graduate students in the LL offices do not follow any specific work schedules and work flexible hours.

The room was mechanically ventilated throughout the measurement campaign. The airflow patterns within the HVAC system for the LL office is illustrated in Figure S1. The supply and return airflows are driven by two independent blowers in the supply and return air ducts, respectively. The supply air typically consists of outdoor air and recirculated return air from the LL office. The outdoor air flows through the outdoor air intake (located on the roof) and mixes with some of the return air from the LL office. Then the mixed air passes through HVAC filters, cooling and heating coils, a humidifier (not activated), and variable air volume (VAV) boxes to remove particulate matter and condition the air before delivering it to the room. The return air from the room was removed by the blower in the return air duct. A part of the return air is recirculated and flows through the recirculation damper to mix with outdoor air, while the rest is exhausted to the outdoor atmosphere via the exhaust damper.

The HVAC system can be operated with a recirculation ratio (RR) between 0 and 1 . The RR is defined as the fractional amount of recirculated return air in the total supply air (outdoor + recirculated return air). A RR of 0 indicates that the supply air only consists of outdoor air. A RR of 1 indicates that all of the return air is recirculated to the room and no outdoor air is introduced. The change of the RR requires systematic adjustment of the exhaust, recirculation, and outdoor air dampers. At a $R R$ of 0 , the exhaust damper is fully opened, the recirculation damper is fully closed, and the outdoor air damper is fully opened. At a RR of 1, the exhaust damper is fully closed, the recirculation damper is fully opened, and the outdoor air damper is fully closed.

During the measurement period, the HVAC system was operated under the pre-existing control logic, aside from several days where we intentionally adjusted the RR to 0 and 1 . This was done to ensure the measurements occur in a realistic built environment under typical building system operational conditions. Under this mode, the 
system provides enthalpy-type economizer control with fixed mixed air temperature. The system automatically adjusts the fraction of incoming outdoor air and recirculated return air in the mixed air to maintain the temperature of the mixed air at pre-determined setpoints. This was implemented by a feedback control which constantly and systematically adjusts the position of the outdoor, recirculation, and exhaust dampers. The reason for maintaining the mixed air at a certain temperature setpoint is to make the supply air temperature more controllable after passing through the cooling and heating elements, thereby ensuring occupant thermal comfort.

Since the mixed air temperature was set at a service setpoint and the outdoor air temperature varied significantly over the measurement period, the HVAC system needed to adjust the RR over a wide range to maintain the desired mixed air temperature, which allowed us to monitor mixing ratios of volatile skin oil ozonolysis products (SOOPs) under different RRs. The fixed mixed air temperature and the significant variations in the outdoor air temperature resulted in a wide range of RRs (RR: 0.1 to 0.8 ) during the measurement period. In addition, the $R R$ was manually maintained at 0 and 1 on certain days to explore the dynamics of SOOPs under such conditions.

\section{Detailed Description of the PTR-TOF-MS Measurements}

The measurement campaign was conducted from February 14 to March 18, 2019. A proton transfer reaction time-of-flight mass spectrometer (PTR-TOF-MS; PTR-TOF 4000, Ionicon Analytik Ges.m.b.H., Innsbruck, Austria) was employed to measure the volume mixing ratios of volatile organic compounds (VOCs) during this period. VOCs with a proton affinity greater than water undergo a proton transfer reaction with hydronium $\left(\mathrm{H}_{3} \mathrm{O}+\right)$ in the drift tube, and the subsequent product ions are detected by the mass spectrometer at a frequency of $1 \mathrm{~Hz}$. The maximum mass to charge ratio $(\mathrm{m} / \mathrm{z})$ of the VOCs that can be detected in this study is 460 . The drift tube was operated at a pressure of $2.2 \mathrm{mbar}$ and a temperature of $60^{\circ} \mathrm{C}$. The $\mathrm{E} / \mathrm{N}$ was $120 \mathrm{Td}$. The abundance of impurity ions (e.g. $\mathrm{O}_{2}{ }^{+}$and $\mathrm{NO}^{+}$) was less than $3 \%$.

The instrument background was checked twice per day with ultra-zero air (Indiana Oxygen Company, Indianapolis, IN, U.S.A.). The instrument was calibrated once per day with a multi-VOC gas standard canister (2 ppm) that includes: methanol, acetonitrile, acetone, isoprene, methyl vinyl ketone, methyl ethyl ketone, benzene, toluene, 1,2-dichloroethylene, vinyl chloride, styrene, p-xylene, 1,3,5-trimethylbenzene, trichloroethylene, 1,2,3,5-tetramethylbenzene, and perchloroethylene. The mixture was diluted with ultra-zero air to 2, 4, 6, and 8 $\mathrm{ppb}$ for calibration. Immediately following the measurement campaign, the PTR-TOF-MS was calibrated with a second multi-VOC gas standard mixture (0.2 ppm) (Apel Riemer Environmental Inc., Miami, Florida, U.S.A.) that includes: acetaldehyde, 6-methyl-5-hepten-2-one (6-MHO), D-limonene, and decamethylcyclopentasiloxane (D5). The mixture was diluted with ultra-zero air to $2,4,6,8,10$, and $12 \mathrm{ppb}$ for calibration.

\section{Additional Measurements}

Mixing ratios of ozone $\left(\mathrm{O}_{3}\right)$ were monitored with a photometric analyzer based on non-dispersive ultraviolet (UV) absorption of $\mathrm{O}_{3}$ at $254 \mathrm{~nm}$ (M400E, Teledyne Technologies Inc., Thousand Oaks, CA, U.S.A.). Mixing ratios of

carbon dioxide $\left(\mathrm{CO}_{2}\right)$ were monitored with a $\mathrm{CO}_{2}$ gas analyzer (LI-830, LI-COR Biosciences, Lincoln, NE, U.S.A.). Room occupancy was monitored with a chair-based temperature sensor array; details can be found in Wagner 
et al. (2021). ${ }^{3}$ Volumetric airflow rates, air temperatures, and relative humidities were measured by an array of sensors installed throughout the HVAC system and recorded by the Niagara/AX framework. Previous measurements of nitrogen oxides $\left(\mathrm{NO}_{\mathrm{x}}\right)$ in the $\mathrm{LL}$ office indicate that indoor concentrations remain $<1 \mathrm{ppb}$.

\section{Automated Valve System for Multi-Location Sampling Across Living Laboratory HVAC System}

An automated valve system was utilized to sample the air at different locations throughout the HVAC system of the LL office (Figure S1). The sampling locations include: the return air duct of the common area (CA), which is an open space outside of the LL office, and 7 points in the HVAC system of the LL office, including the outdoor air duct (OA), before the HVAC filter bank (Pre-fil), after the HVAC filter bank (Post-fil), after the humidifier (HF), supply air duct in the small mechanical room $(S A(S M))$, return air duct in the small mechanical room $(R A(S M))$, and return air duct in the penthouse $(\mathrm{RA}(\mathrm{PH}))$. The small mechanical room is immediately adjacent to the $\mathrm{LL}$ office, while it is about $9.5 \mathrm{~m}$ away from the penthouse mechanical room, where the AHU of the LL office is located. The supply and return air ducts are installed above the ceiling from the AHU in the penthouse to the small mechanical room and then connected to the LL office. VOCs measured in the outdoor air duct (OA) represent the outdoor air, which is directly drawn through the outdoor air intake on the roof. The air in the supply air duct in the small mechanical room (SA(SM)) represents the conditioned supply air immediately before delivery to the room. The sampling location in the return air duct in the small mechanical room (RA(SM)) is $1.2 \mathrm{~m}$ from the return air grille in the LL office, through which the room air is drawn to the return duct. The air at RA(SM) represents the well-mixed room air. The sampling location in the return air duct in the penthouse $(R A(R H))$ is 20 m downstream of the RA(SM) location, which represents the air being exhausted to the outdoor atmosphere.

The multi-location sampling was enabled by a 'common-outlet' type, programmable multi-flow path selector (EUTA-2VLSC8MWE2, Valco Instruments Co. Inc., Houston, TX, U.S.A.). The selected flow path outlet was connected to the PTR-TOF-MS, $\mathrm{O}_{3}$ gas analyzer, and $\mathrm{CO}_{2}$ gas analyzer to sample the air at the desired location. The unselected streams were purged by a rough pump to prevent accumulation of stagnant air in the lines. This was done to eliminate a time delay in sampling. The flow rate of the selected stream was maintained at 9 LPM with a vacuum pump. PFA tubes (3/8" OD) were used as the sampling lines connecting the sampling location to the multi-flow path selector. A PTFE membrane filter was installed at the inlet of each sampling line to remove particulate matter and was replaced every several days. The residence time of the sample air was $<4 \mathrm{~s}$.

Two sampling sequences were developed for the multi-flow path selector: (1) a temporal sequence focusing on the temporal variation in VOC concentrations in the room and (2) a spatial sequence focusing on differences in VOC concentrations at different locations in the HVAC system. The temporal sequence consists of: 5 min at OA, 5 min at SA(SM), and 20 min at RA(SM). The spatial sequence consists of: 4 min at OA, 4 min at Pre-fil, 4 min at Post-fil, 4 min at HF, 4 min at $\mathrm{SA}(\mathrm{SM}), 4 \mathrm{~min}$ at $\mathrm{RA}(\mathrm{SM}), 3 \mathrm{~min}$ at $\mathrm{RA}(\mathrm{PH})$, and $3 \mathrm{~min}$ at $\mathrm{CA}$. Both the temporal and spatial sequences have a full cycle of $30 \mathrm{~min}$. The $\mathrm{VOC}, \mathrm{O}_{3}$, and $\mathrm{CO}_{2}$ data during the first 2 min after valve switching was rejected for analysis in order to minimize any tubing delay artifacts. 


\section{Data Analysis}

\section{$\underline{\text { SOOP Concentration Calculation }}$}

The ion signals ( $\mathrm{m} / \mathrm{z}$; protonated parent ions and fragment ions) used to calculate the volume mixing ratios (concentrations) of SOOPs (6-MHO, 4-oxopentanal (4-OPA), and decanal) followed that of Wisthaler and Weschler $(2010)^{4}$. The ion signals of $\mathrm{C}_{8} \mathrm{H}_{15} \mathrm{O}^{+}$and $\mathrm{C}_{8} \mathrm{H}_{13}{ }^{+}$were used for 6-MHO. The ion signals of $\mathrm{C}_{5} \mathrm{H}_{9} \mathrm{O}_{2}{ }^{+}$were used for 4-OPA. The ion signals of $\mathrm{C}_{10} \mathrm{H}_{21} \mathrm{O}^{+}$and $\mathrm{C}_{10} \mathrm{H}_{19}{ }^{+}$were used for decanal. The instrument response exhibited small daily variations during the measurements. The daily normalized sensitivity was calculated as the slope of the linear regression between the normalized counts per second (ncps) and the concentration (ppb) of the calibration standard to estimate the concentration of 6-MHO, decanal, and 4-OPA on each day. However, the instrument was only calibrated with a calibration standard for 6-MHO after the measurement campaign. To account for daily variations in instrument response, the following correction procedure was implemented for the after-campaign normalized sensitivity of $6-\mathrm{MHO}$ in order to estimate the daily normalized sensitivities.

First, the after-campaign calibration data was used to estimate the normalized sensitivity of 6-MHO and benzene. Then, we estimated the ratios of the after-campaign normalized sensitivity of 6-MHO to that of benzene, which was also used for daily calibrations during the measurements. Benzene was selected for estimating the ratios as it exhibited small variations in its daily normalized sensitivity during the campaign. After that, we multiplied the ratio for 6-MHO with the daily normalized sensitivity of benzene to get the daily normalized sensitivity of 6 $\mathrm{MHO}$, which was used for the concentration calculation on each day.

A previous study indicated that PTR-TOF-MS calibration factors have a variability of about $15-30 \%$ for oxygenated compounds. ${ }^{5}$ In this study, the uncertainty of the calculated concentration of 6 -MHO was estimated to be within $20.5-35.5 \%$, which accounts for both the variability in the after-campaign calibration and the day-today variations in instrument response. Due to the lack of 4-OPA and decanal calibration standards, we used a default sensitivity factor, assuming a constant reaction rate coefficient of $2.5 \times 10^{-9} \mathrm{~cm}^{3} \mathrm{~s}^{-1}$ for the proton transfer reactions of the parent compounds. ${ }^{6}$ We estimated the uncertainty to be $\pm 50 \% .{ }^{6,7}$ The background obtained via ultra-zero air measurement was subtracted from the calculation concentration on each day. The detection limits (60 s) of 6-MHO, 4-OPA, and decanal were $0.013,0.014$, and $0.006 \mathrm{ppb}$. 
Figures

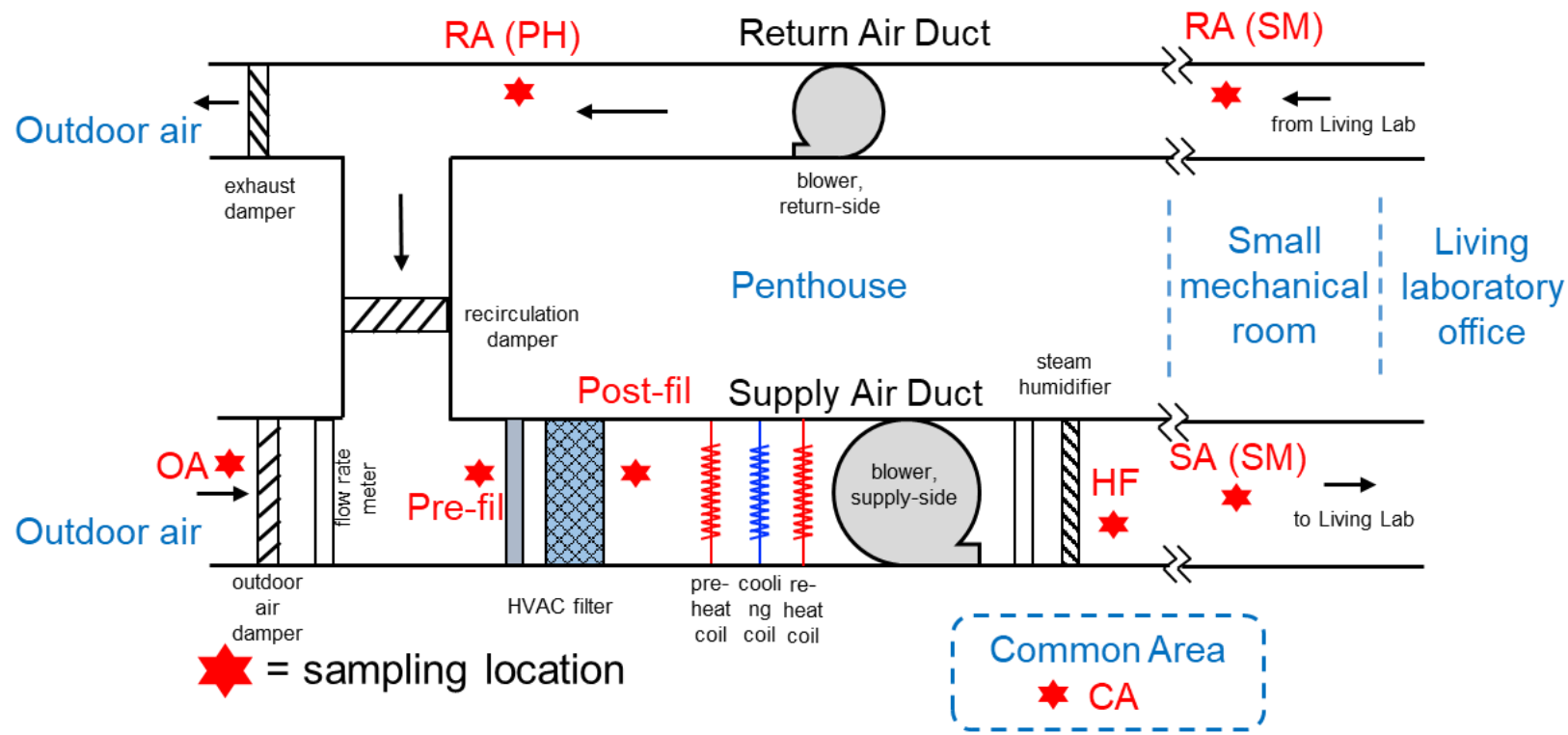

Figure S1. Schematic of the HVAC system of the Herrick Living Laboratory office. The star labels indicate the sampling locations for the real-time $\mathrm{VOC}, \mathrm{O}_{3}$, and $\mathrm{CO}_{2}$ measurements. 


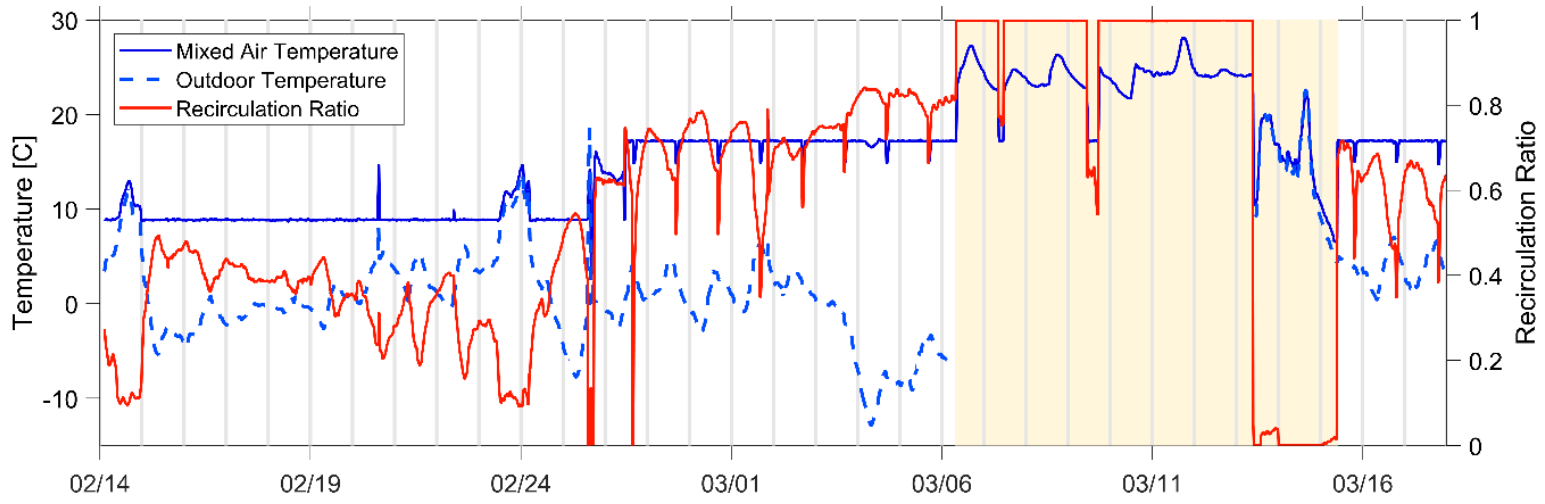

Figure S2. Time-series of the mixed air temperature, outdoor air temperature, and recirculation ratio (RR) for the HVAC system of the Herrick Living Laboratory office. The light yellow region indicates the override mode, when the RR was deliberately maintained at 0 and 1. 

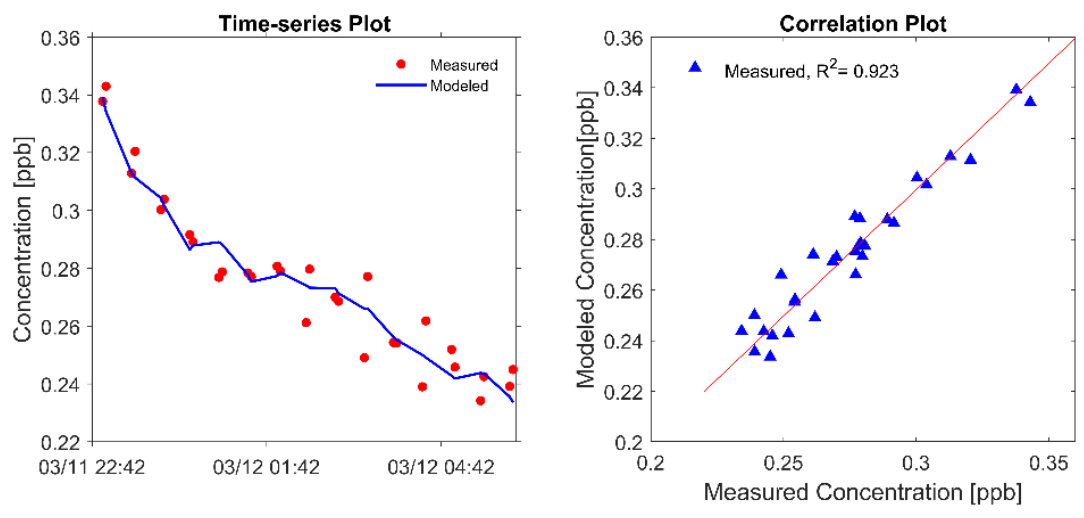

(a.)
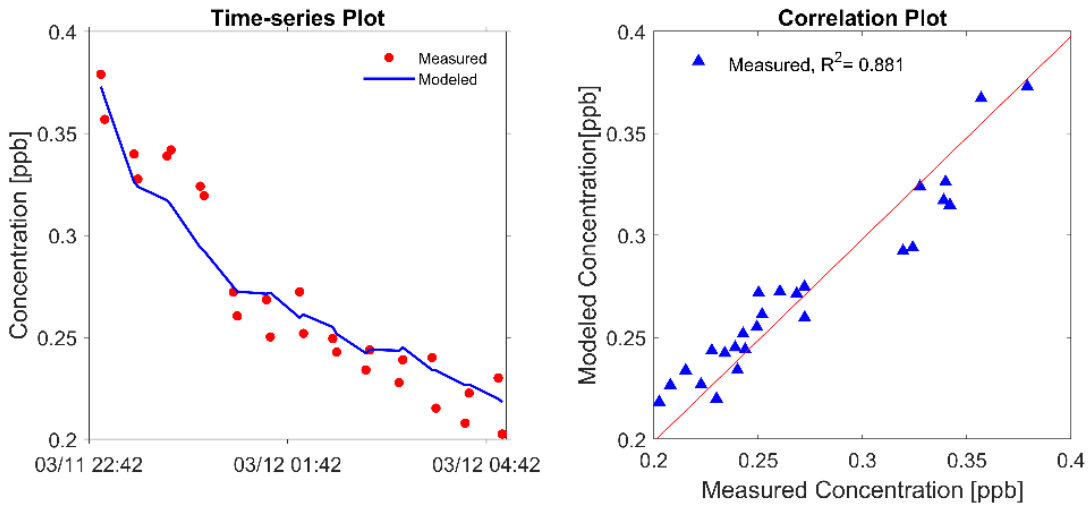

(b.)
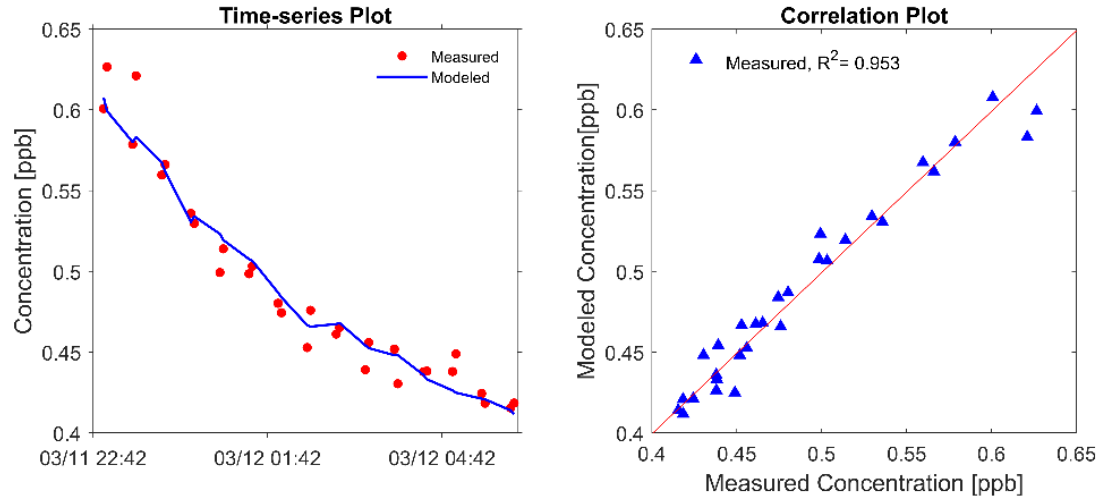

(c.)
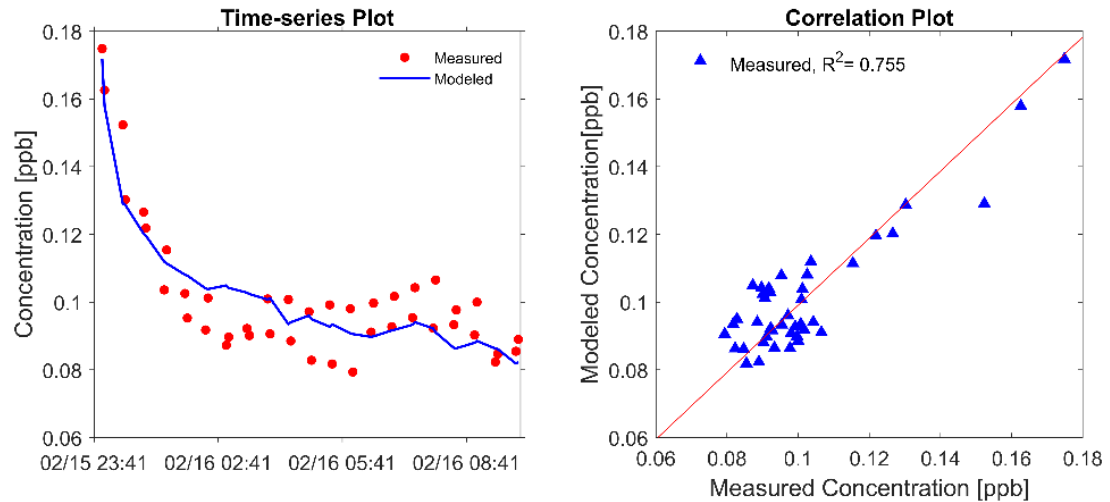

(d.) 

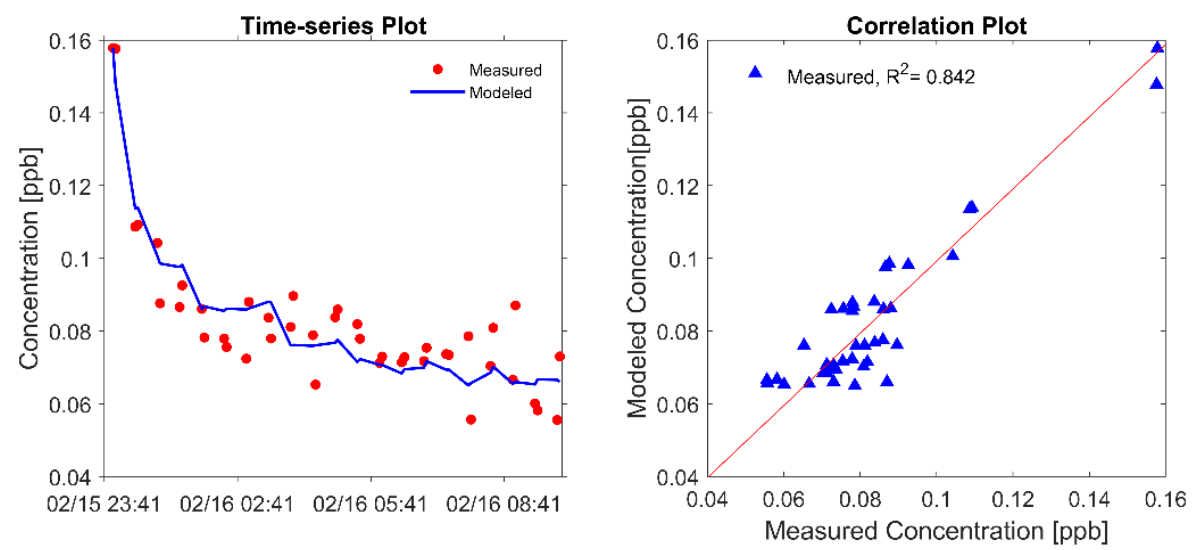

(e.)
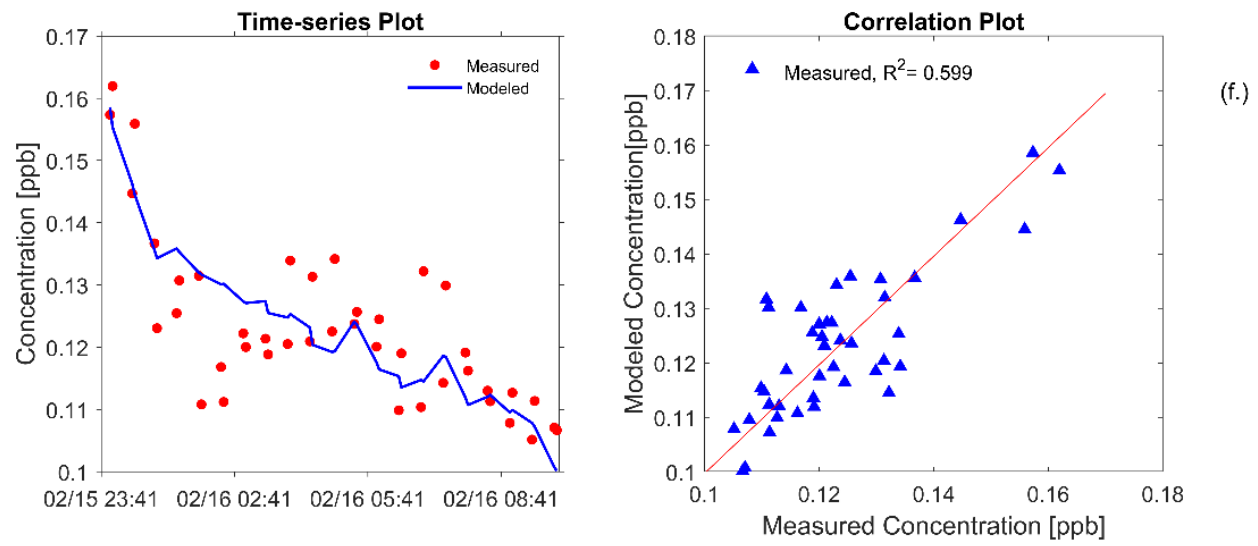

Figure S3. Comparison between measured and modeled concentrations for decanal (a. and d.), 6-MHO (b. and e.), and 4-OPA (c. and f.) during unoccupied periods in the Herrick Living Laboratory office. Partitioning of SOOPs between the gas phase and surface reservoir was treated as a net surface emission rate. 

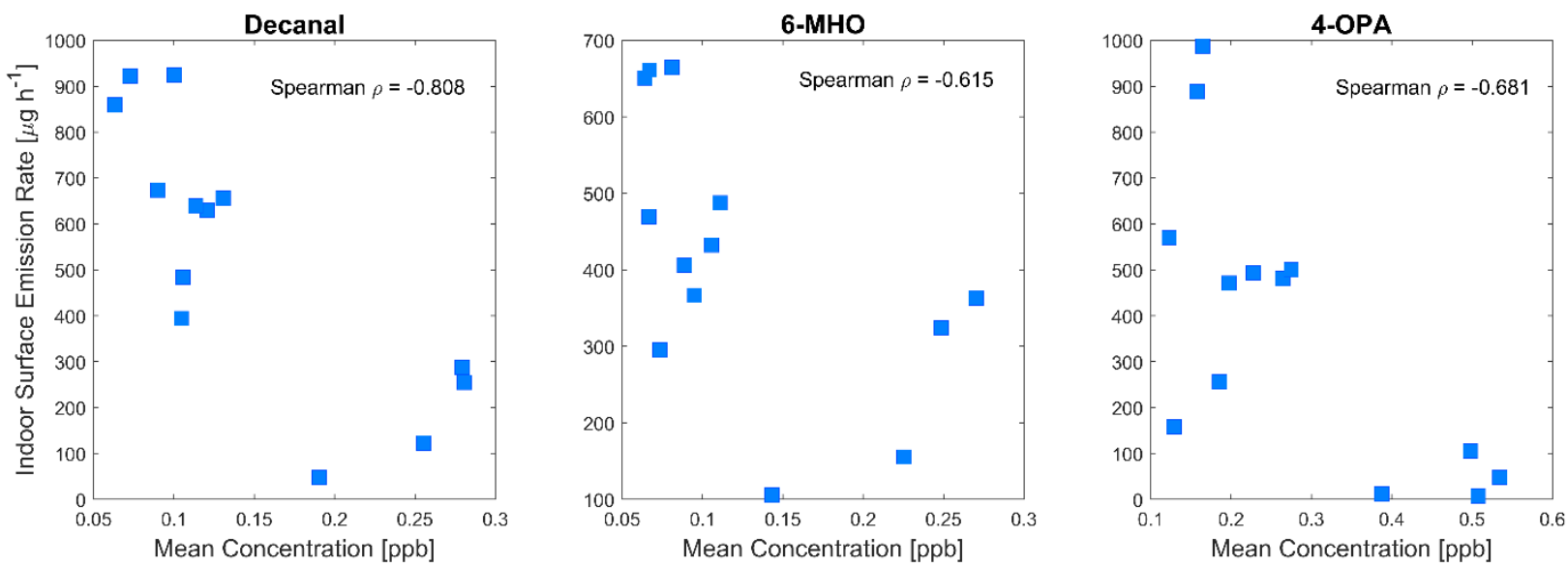

Figure S4. Correlations between net indoor surface emission rates and mean indoor concentrations for decanal, 6-MHO, and 4-OPA. The correlations are reflected by the Spearman's $\rho$. 


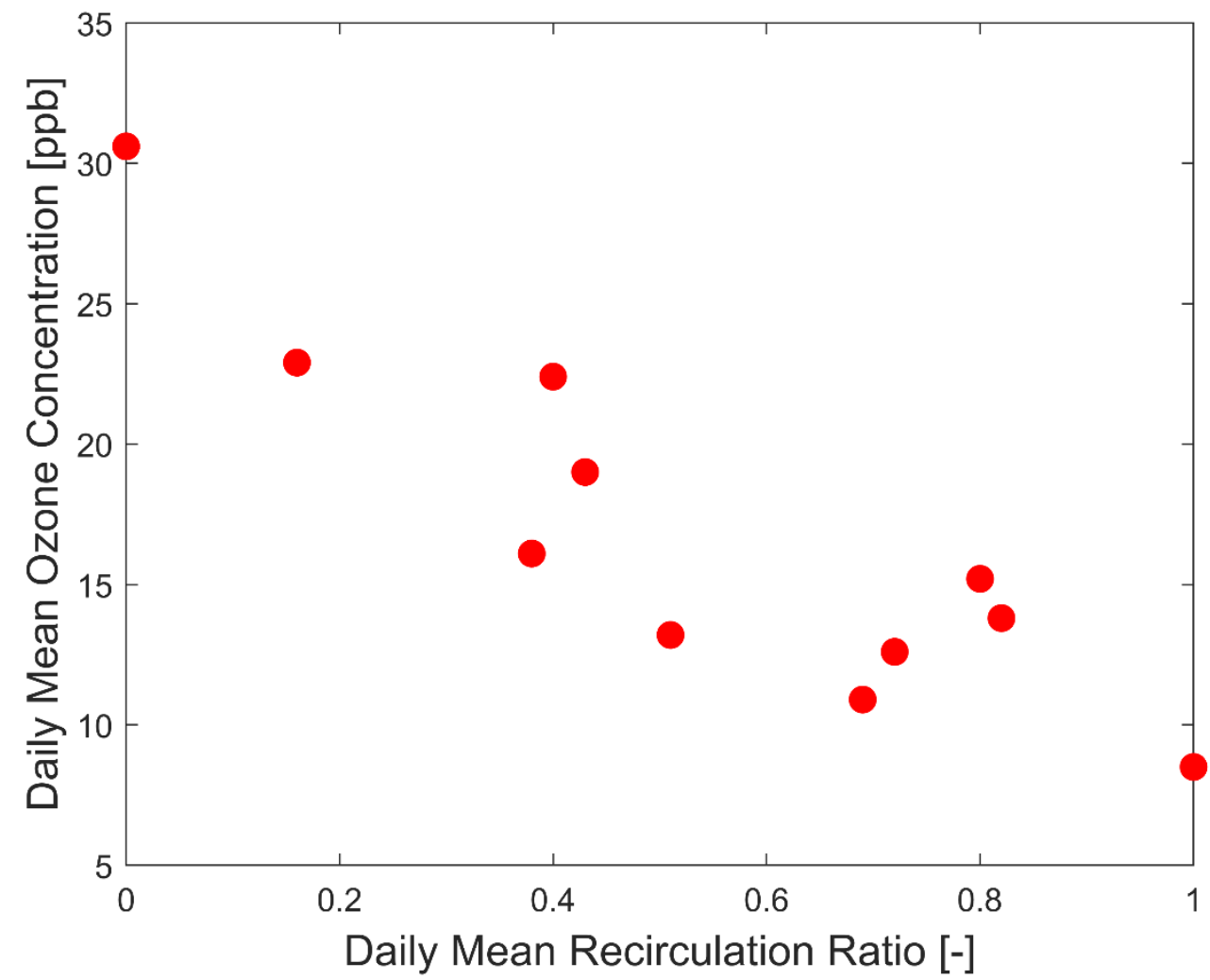

Figure S5. The daily mean indoor ozone concentration as a function of the recirculation ratio. 


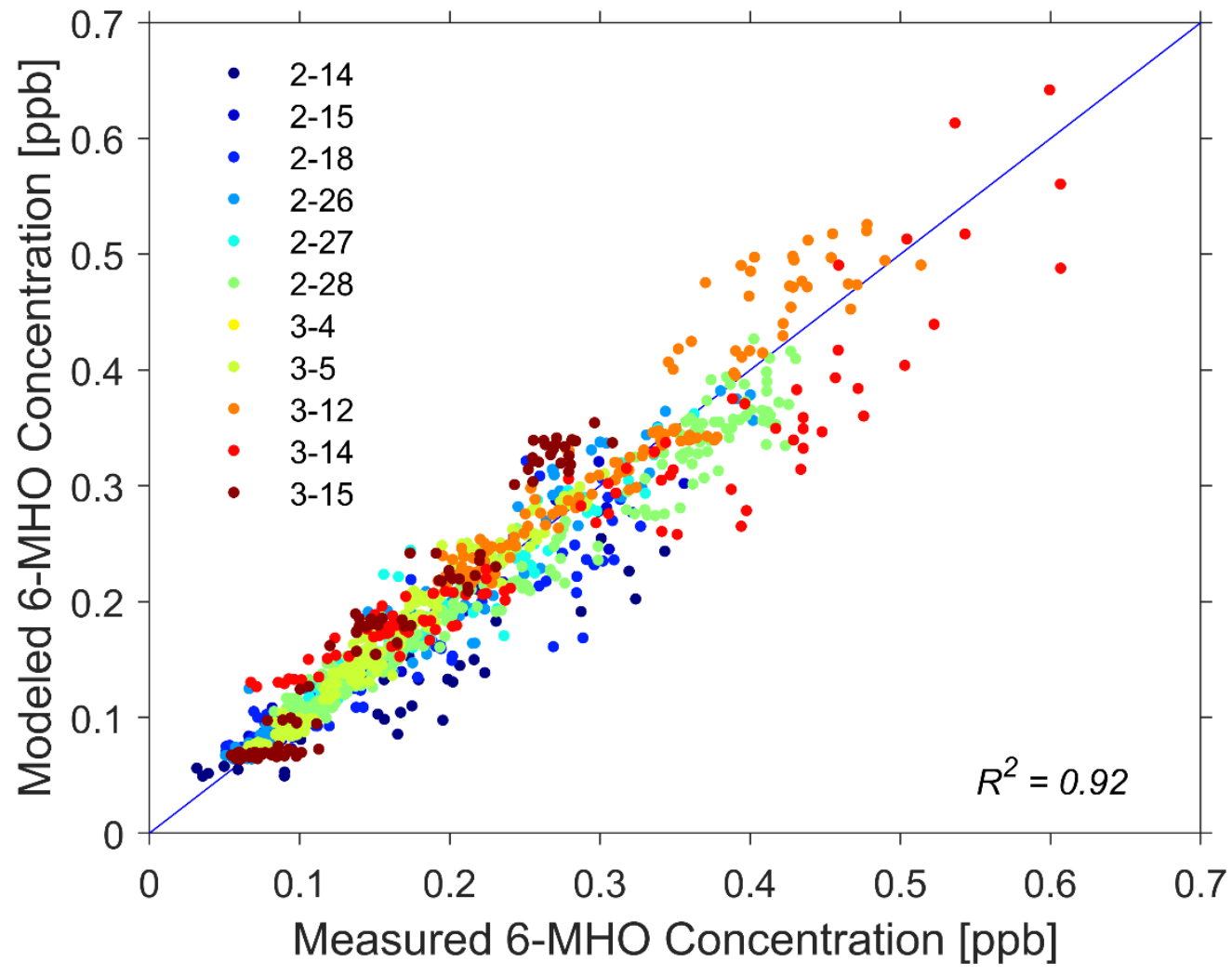

Figure S6. Comparison between measured and modeled concentrations of 6-MHO. 


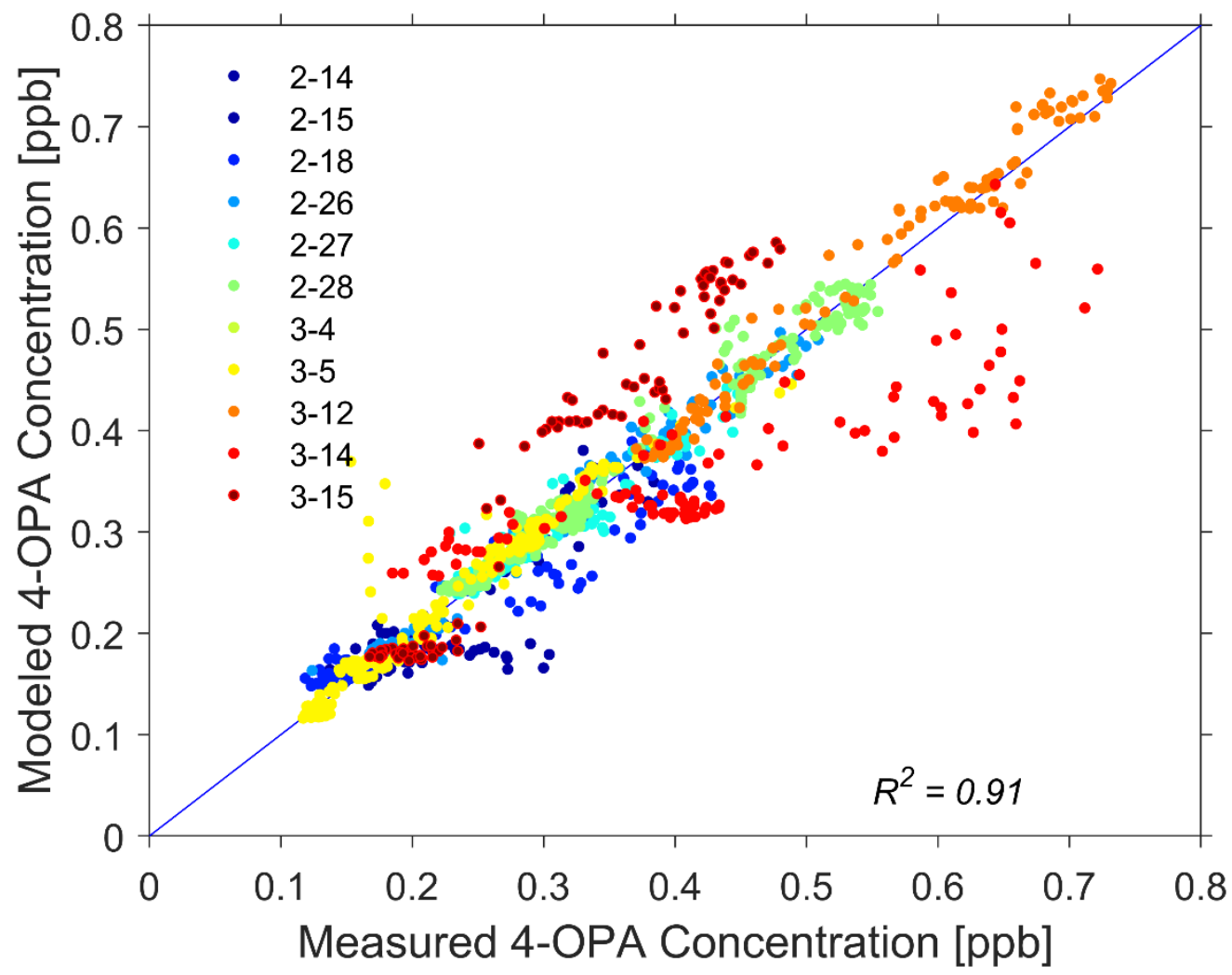

Figure S7. Comparison between measured and modeled concentrations of 4-OPA. 


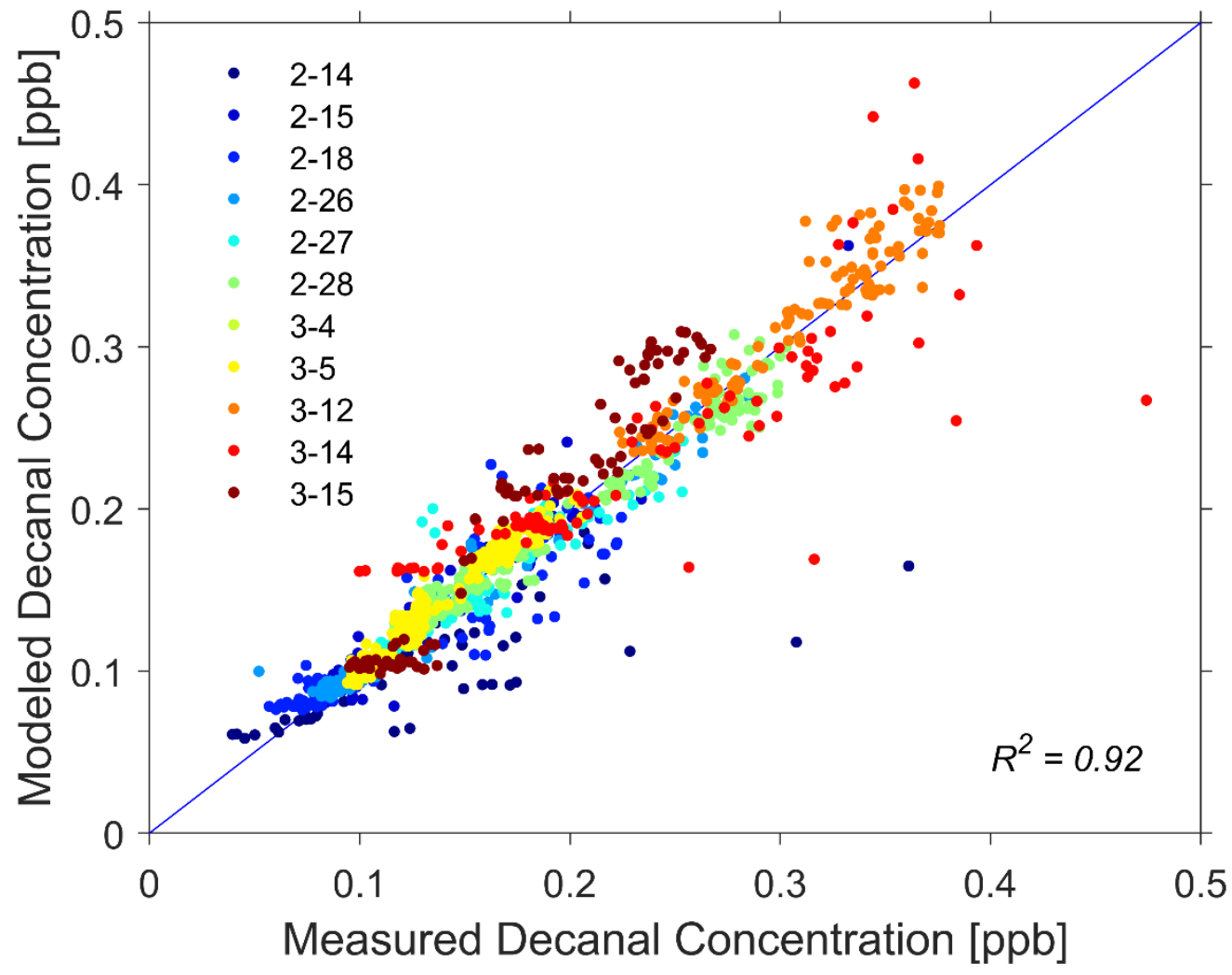

Figure S8. Comparison between measured and modeled concentrations of decanal. 


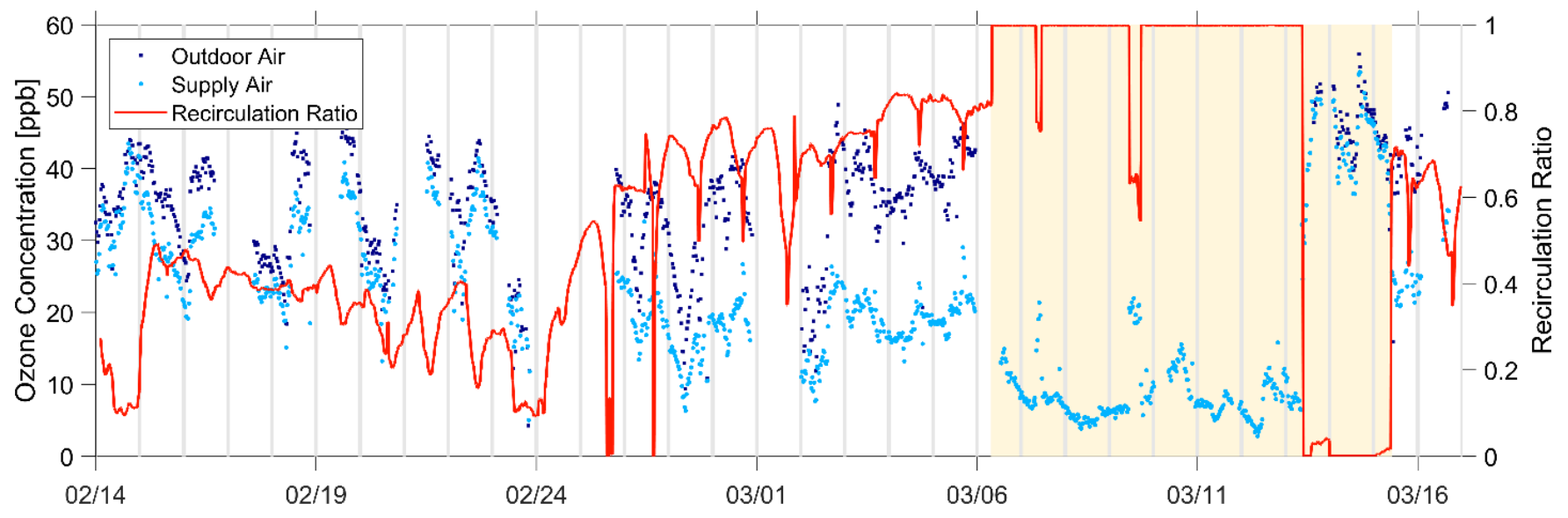

Figure S9. Time-series of the outdoor air ozone concentration, supply air ozone concentration, and recirculation ratio (RR) for the HVAC system of the Herrick Living Laboratory office. The light yellow region indicates the override mode, when the RR was deliberately maintained at 0 and 1. 


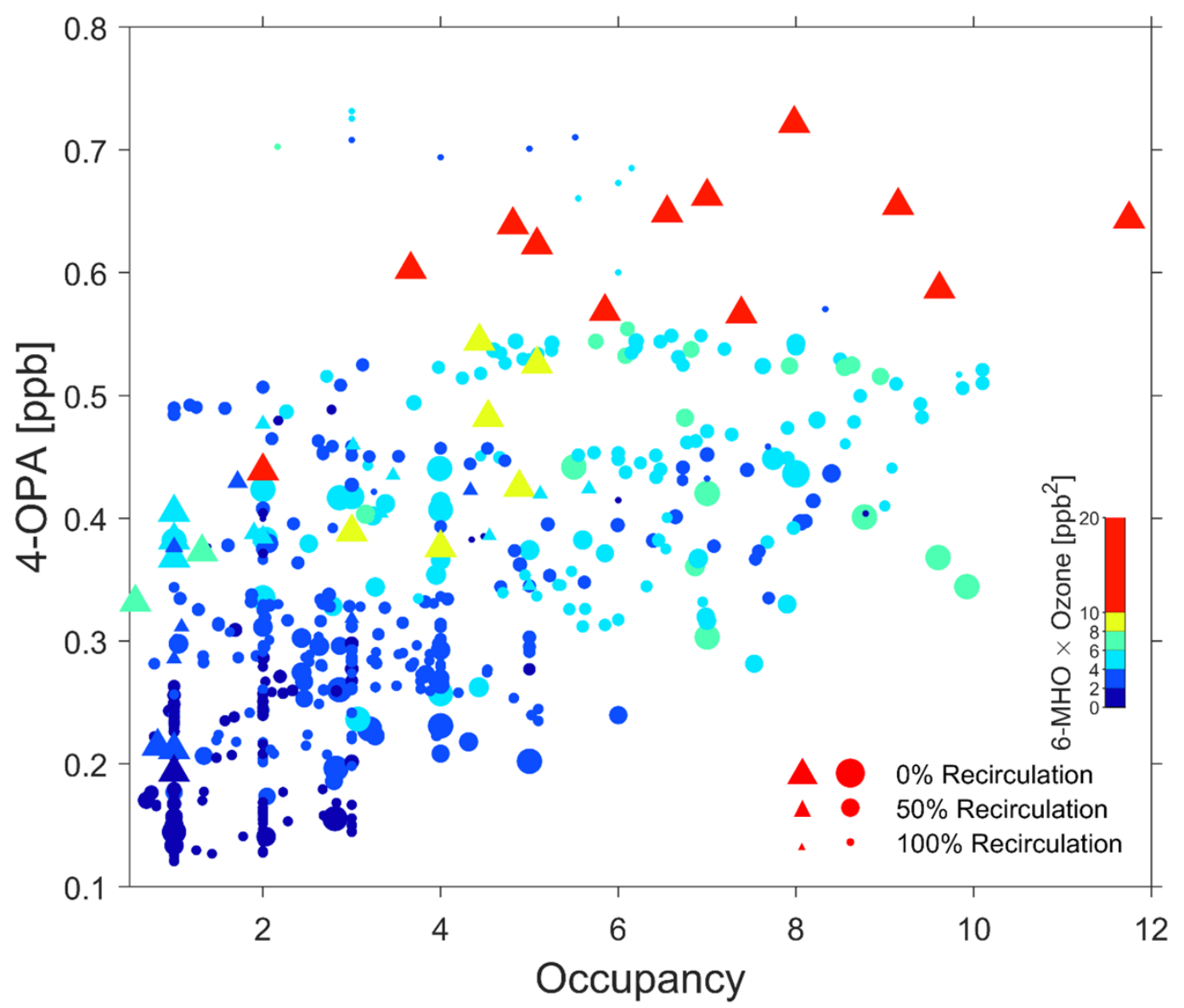

Figure S10. Indoor concentrations of 4-OPA as a function of office occupancy. The size and color of the circular markers indicate the recirculation ratio and the product of the 6-MHO and ozone concentrations, respectively, for data collected prior to March 13,2019 . The size and color of the triangular markers indicate the recirculation ratio and indoor $\mathrm{O}_{3}$ concentration, respectively, for data collected on March 14 and 15, 2019 when enhanced $S_{\text {surface }}$ was observed. 
Table S1. Key parameters determined by applying the material balance model.

\begin{tabular}{|c|c|c|c|}
\hline & $k_{a p p}\left(\mathrm{~m}^{3} \mathrm{~s}^{-1}\right)$ & Yield (mean \pm s.d.) & Yield (median (25th-75th)) \\
\hline $6-\mathrm{MHO}$ & 0.00081 & $0.048 \pm 0.021$ & $0.042(0.032-0.061)$ \\
\hline 4-OPA & 0.00028 & $0.018 \pm 0.0071$ & $0.016(0.011-0.023)$ \\
\hline Decanal & 0.0004 & $0.024 \pm 0.01$ & $0.02(0.016-0.03)$ \\
\hline \multicolumn{2}{|c|}{ Ozone Deposition Velocity } & $v_{\text {dep }}$ (mean \pm s.d.) & $v_{d e p}$ (median (25th-75th)) \\
\hline \multicolumn{2}{|c|}{ Indoor Surfaces $\left(\mathrm{cm} \mathrm{s}^{-1}\right)$} & $0.045 \pm 0.0083$ & $0.046(0.033-0.05)$ \\
\hline \multicolumn{2}{|c|}{ Per Person $\left(\mathrm{cm} \mathrm{s}^{-1} \mathrm{p}^{-1}\right)$} & $1.35 \pm 0.63$ & $1.23(0.63-1.6)$ \\
\hline
\end{tabular}


Table S2. Summary of daily mean source rates, recirculation ratios, occupancy, ozone concentrations, emission factors, VOC concentrations, and I/O ratios.

\begin{tabular}{|c|c|c|c|c|c|c|c|c|c|c|c|c|}
\hline \multirow[b]{2}{*}{ 6-MHO } & \multirow[b]{2}{*}{ 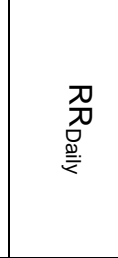 } & \multirow{2}{*}{ 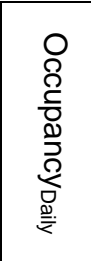 } & \multirow[b]{2}{*}{$\begin{array}{c}\mathrm{O}_{3, \text { Daily }} \\
\text { (ppb) }\end{array}$} & \multicolumn{6}{|c|}{ Source Rate Daily $\left(\mu \mathrm{g} \mathrm{h}^{-1}\right)$} & \multirow[b]{2}{*}{$\begin{array}{c}\text { EF }_{\text {Daily }} \\
\left(\mu \mathrm{g} \mathrm{h}^{-1} \mathrm{p}^{-1}\right)\end{array}$} & \multirow[b]{2}{*}{$\begin{array}{c}{[\mathrm{C}]_{\text {Daily }}} \\
(\mathrm{ppb})\end{array}$} & \multirow[b]{2}{*}{ I/ODaily } \\
\hline & & & & Total & Outdoor & $\begin{array}{l}\text { Recirculated } \\
\text { Room Air }\end{array}$ & $\begin{array}{l}\text { Occupant- } \\
\text { Associated }\end{array}$ & $\begin{array}{c}\text { Indoor } \\
\text { Surfaces }\end{array}$ & $\begin{array}{c}\text { Gas-Phase } \\
\text { Reactions }\end{array}$ & & & \\
\hline 14-Feb & $0.16 \pm 0$ & $2.3 \pm 2$ & $22.9 \pm 2.6$ & $1992 \pm 1006$ & $147 \pm 89$ & $139 \pm 53$ & $961 \pm 1000$ & 716 & $29 \pm 12$ & $382 \pm 51$ & $0.14 \pm 0.08$ & $8.0 \pm 4.5$ \\
\hline 15-Feb & $0.43 \pm 0$ & $1.7 \pm 2$. & $19.0 \pm 3.4$ & $2140 \pm 721$ & $172 \pm 92$ & $677 \pm 390$ & $476 \pm 600$ & 797 & $18 \pm 6$ & $290 \pm 34$ & $0.15 \pm 0.08$ & $5.3 \pm 6.1$ \\
\hline 18-Feb & $0.38 \pm 0$. & $1.7 \pm 2$. & $16.1 \pm 2.6$ & $2100 \pm 982$ & $84 \pm 38$ & $516 \pm 297$ & $686 \pm 936$ & 791 & $22 \pm 13$ & $374 \pm 104$ & $0.14 \pm 0.09$ & $9.4 \pm 5.4$ \\
\hline 26-Feb & $0.61 \pm 0$. & $2.4 \pm 2$. & $13.1 \pm 2.0$ & $2538 \pm 1224$ & $147 \pm 385$ & $1183 \pm 777$ & $667 \pm 865$ & 517 & $24 \pm 14$ & $271 \pm 68$ & $0.17 \pm 0.11$ & $10.0 \pm 7.7$ \\
\hline 27-Feb & $0.69 \pm 0$. & $2.0 \pm 2$. & $10.9 \pm 2.6$ & $2528 \pm 724$ & $149 \pm 95$ & $1533 \pm 553$ & $354 \pm 458$ & 474 & $19 \pm 10$ & $172 \pm 45$ & $0.17 \pm 0.06$ & $4.6 \pm 1.8$ \\
\hline 28-Feb & $0.72 \pm 0$ & $2.5 \pm 2$. & $12.6 \pm 1.2$ & \begin{tabular}{|l|}
$2933 \pm 950$ \\
\end{tabular} & $80 \pm 50$ & $1828 \pm 733$ & $536 \pm 602$ & 461 & $28 \pm 15$ & $204 \pm 22$ & $0.21 \pm 0.11$ & $10.2 \pm 8.3$ \\
\hline 4-Mar & $0.82 \pm 0$ & $1.8 \pm 1$. & $13.8 \pm 1.7$ & $2258 \pm 700$ & $38 \pm 24$ & $1463 \pm 533$ & $444 \pm 452$ & 294 & $19 \pm 6$ & $239 \pm 29$ & $0.15 \pm 0.06$ & $10.2 \pm 9.9$ \\
\hline \begin{tabular}{|l} 
5-Mar \\
\end{tabular} & $0.80 \pm 0$ & $2.4 \pm 2$. & $15.2 \pm 1.4$ & $3035 \pm 1206$ & $66 \pm 28$ & $1744 \pm 799$ & $767 \pm 902$ & 435 & $24 \pm 12$ & $309 \pm 54$ & $0.17 \pm 0.09$ & $6.1 \pm 7.2$ \\
\hline 12-Mar & $1.00 \pm 0$ & $2.7 \pm 2$. & $8.5 \pm 3.2$ & $4981 \pm 1279$ & $0 \pm 0$ & $4131 \pm 1174$ & $399 \pm 506$ & 421 & $26 \pm 16$ & $136 \pm 59$ & $0.32 \pm 0.08$ & $\mathrm{NaN}$ \\
\hline 14-Mar & $0.00 \pm 0$ & $2.5 \pm 3$ & $30.6 \pm 3.5$ & $4509 \pm 1983$ & $761 \pm 274$ & $0 \pm 0$ & $1493 \pm 1964$ & 2179 & $76 \pm 39$ & $586 \pm 137$ & $0.26 \pm 0.15$ & $4.2 \pm 1.7$ \\
\hline 15-Mar & $0.40 \pm 0$ & $1.5 \pm 1$. & $22.4 \pm 6.3$ & $2815 \pm 1174$ & $112 \pm 55$ & $1089 \pm 1009$ & $505 \pm 599$ & 1076 & $33 \pm 10$ & $351 \pm 71$ & $0.15 \pm 0.08$ & $7.1 \pm 3.2$ \\
\hline \multicolumn{13}{|c|}{ 4-OPA } \\
\hline 14-Feb & $0.16 \pm 0$. & $2.3 \pm 2$. & $22.9 \pm 2.6$ & $2742 \pm 383$ & $564 \pm 178$ & $285 \pm 81$ & $305 \pm 328$ & 1086 & $502 \pm 250$ & $121 \pm 30$ & $0.27 \pm 0.1$ & $3.6 \pm 0.6$ \\
\hline $15-F e b$ & $0.43 \pm 0$. & $1.7 \pm 2$. & $19.0 \pm 3.4$ & $2396 \pm 409$ & $254 \pm 98$ & $951 \pm 333$ & $165 \pm 215$ & 683 & $343 \pm 113$ & $100 \pm 20$ & $0.23 \pm 0.06$ & $5.3 \pm 1.7$ \\
\hline 18-Feb & $0.38 \pm 0$ & $1.7 \pm 2$. & $16.1 \pm 2.6$ & $2519 \pm 449$ & $202 \pm 68$ & $821 \pm 361$ & $189 \pm 257$ & 970 & $337 \pm 206$ & $103 \pm 29$ & $0.23 \pm 0.1$ & $6.1 \pm 1.7$ \\
\hline 26-Feb & $0.61 \pm 0$ & $2.4 \pm 2$. & $13.1 \pm 2.0$ & $3324 \pm 1101$ & $367 \pm 554$ & $2005 \pm 921$ & $183 \pm 238$ & 448 & $321 \pm 154$ & $74 \pm 19$ & $0.29 \pm 0.11$ & $4.5 \pm 1$ \\
\hline 27-Feb & $0.69 \pm 0$ & $2.0 \pm 2$. & $10.9 \pm 2.6$ & $3448 \pm 450$ & $251 \pm 89$ & $2382 \pm 423$ & $97 \pm 126$ & 490 & $227 \pm 78$ & $47 \pm 12$ & $0.31 \pm 0.05$ & $4.4 \pm 1$ \\
\hline 28-Feb & $0.72 \pm 0$ & $2.5 \pm 2$ & $12.6 \pm 1.2$ & $3975 \pm 786$ & $212 \pm 108$ & $2827 \pm 761$ & $147 \pm 166$ & 488 & $300 \pm 106$ & $56 \pm 6$ & $0.35 \pm 0.1$ & $5.6 \pm 0.9$ \\
\hline 4-Mar & $0.82 \pm 0$ & $1.8 \pm 1$. & $13.8 \pm 1.7$ & $2616 \pm 728$ & $59 \pm 36$ & $2060 \pm 717$ & $122 \pm 124$ & 155 & $221 \pm 83$ & $66 \pm 8$ & $0.22 \pm 0.08$ & $8.1 \pm 4.1$ \\
\hline 5-Mar & $0.80 \pm 0$ & $2.4 \pm 2$ & $15.2 \pm 1.4$ & $3402 \pm 918$ & $95 \pm 59$ & $2466 \pm 882$ & $211 \pm 248$ & 292 & $338 \pm 166$ & $85 \pm 15$ & $0.27 \pm 0.1$ & $6.9 \pm 1$ \\
\hline 12-Mar & $1.00 \pm 0$ & $2.7 \pm 2$. & $8.5 \pm 3.2$ & $6245 \pm 1316$ & $0 \pm 0$ & $5743 \pm 1308$ & $110 \pm 139$ & 84 & $303 \pm 177$ & $37 \pm 16$ & $0.56 \pm 0.11$ & $\mathrm{NaN}$ \\
\hline 14-Mar & $0.00 \pm 0$. & $2.5 \pm 3$. & $30.6 \pm 3.5$ & $4706 \pm 576$ & $789 \pm 198$ & $0 \pm 0$ & $410 \pm 540$ & 2471 & $1035 \pm 407$ & $161 \pm 38$ & $0.42 \pm 0.15$ & $6.5 \pm 1.6$ \\
\hline 15-Mar & $0.40 \pm 0$. & $1.5 \pm 1.8$ & $22.4 \pm 6.3$ & $4240 \pm 1543$ & $239 \pm 123$ & $1789 \pm 1529$ & $139 \pm 165$ & 1589 & $485 \pm 120$ & $97 \pm 19$ & $0.29 \pm 0.1$ & $9.3 \pm 2.7$ \\
\hline \multicolumn{13}{|l|}{ Decanal } \\
\hline 14-Feb & $0.16 \pm 0$ & $2.3 \pm 2$ & $22.9 \pm 2.6$ & $1887 \pm 614$ & $197 \pm 46$ & $158 \pm 36$ & $587 \pm 611$ & 946 & $\mathrm{NaN}$ & $233 \pm 31$ & $0.13 \pm 0.04$ & $5.6 \pm 3.9$ \\
\hline \begin{tabular}{|l|}
$15-\mathrm{Feb}$ \\
\end{tabular} & $0.43 \pm 0$ & $1.7 \pm 2$. & $19.0 \pm 3.4$ & $2195 \pm 432$ & $96 \pm 35$ & $738 \pm 227$ & $291 \pm 366$ & 1070 & $\mathrm{NaN}$ & $176 \pm 21$ & $0.13 \pm 0.04$ & $9.7 \pm 9$ \\
\hline 18-Feb & $0.38 \pm 0$. & $1.7 \pm 2$. & $16.1 \pm 2.6$ & $1975 \pm 596$ & $47 \pm 24$ & $456 \pm 166$ & $419 \pm 571$ & 1053 & $\mathrm{NaN}$ & $228 \pm 64$ & $0.11 \pm 0.04$ & $18 \pm 12.7$ \\
\hline 26-Feb & $0.61 \pm 0$. & $2.4 \pm 2$. & $13.1 \pm 2.0$ & $2585 \pm 791$ & $137 \pm 285$ & $1351 \pm 516$ & $407 \pm 528$ & 690 & $\mathrm{NaN}$ & $165 \pm 41$ & $0.15 \pm 0.05$ & $13.1 \pm 12.2$ \\
\hline 27-Feb & $0.69 \pm 0$. & $2.0 \pm 2$. & $10.9 \pm 2.6$ & $2580 \pm 375$ & $85 \pm 43$ & $1688 \pm 246$ & $216 \pm 280$ & 592 & $\mathrm{NaN}$ & $105 \pm 27$ & $0.15 \pm 0.03$ & $10.7 \pm 5.8$ \\
\hline $28-F e b$ & $0.72 \pm 0$ & $2.5 \pm 2$. & $12.6 \pm 1.2$ & $3072 \pm 577$ & $56 \pm 32$ & $2029 \pm 444$ & $328 \pm 368$ & 659 & $\mathrm{NaN}$ & $125 \pm 13$ & $0.18 \pm 0.05$ & $17.4 \pm 12.4$ \\
\hline 4-Mar & $0.82 \pm 0$. & $1.8 \pm 1$. & $13.8 \pm 1.7$ & $2424 \pm 406$ & $18 \pm 15$ & $1692 \pm 297$ & $271 \pm 276$ & 444 & $\mathrm{NaN}$ & $145 \pm 18$ & $0.14 \pm 0.03$ & $25.7 \pm 22.3$ \\
\hline 5-Mar & $0.80 \pm 0$ & $2.4 \pm 2$ & $15.2 \pm 1.4$ & $2701 \pm 696$ & $30 \pm 14$ & $1844 \pm 426$ & $468 \pm 551$ & 358 & $\mathrm{NaN}$ & $187 \pm 33$ & $0.15 \pm 0.04$ & $16.3 \pm 18.8$ \\
\hline 12-Mar & $1.00 \pm 0$. & $2.7 \pm 2$. & $8.5 \pm 3.2$ & $5266 \pm 708$ & $0 \pm 0$ & $4946 \pm 637$ & $244 \pm 309$ & 303 & $\mathrm{NaN}$ & $83 \pm 36$ & $0.31 \pm 0.04$ & $\mathrm{NaN}$ \\
\hline 14-Mar & $0.00 \pm 0$ & $2.5 \pm 3$. & $30.6 \pm 3.5$ & $4217 \pm 1206$ & $794 \pm 126$ & $0 \pm 0$ & $912 \pm 1199$ & 2511 & $\mathrm{NaN}$ & $358 \pm 84$ & $0.22 \pm 0.06$ & $3.8 \pm 1.2$ \\
\hline \begin{tabular}{|l} 
15-Mar \\
\end{tabular} & $0.40 \pm 0$ & $1.5 \pm 1.8$ & $22.4 \pm 6.3$ & $3316 \pm 938$ & $276 \pm 83$ & $1324 \pm 860$ & $308 \pm 366$ & 1408 & $\mathrm{NaN}$ & $215 \pm 43$ & $0.17 \pm 0.05$ & $6 \pm 2.1$ \\
\hline
\end{tabular}

*The subscript "Daily" indicates the daily mean value. 
Table S3. Summary of source rates, recirculation ratios, occupancy, ozone concentrations, VOC concentrations, and I/O ratios during the high occupancy period (10:00-18:00).

\begin{tabular}{|c|c|c|c|c|c|c|c|c|c|c|c|}
\hline \multirow[b]{2}{*}{ 6-MHO } & \multirow[b]{2}{*}{$\begin{array}{l}\text { ग0 } \\
\text { ग } \\
\dot{1} \\
\infty\end{array}$} & \multirow{2}{*}{ 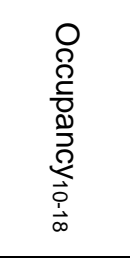 } & \multirow[b]{2}{*}{$\begin{array}{c}\mathrm{O}_{3,10-18} \\
(\mathrm{ppb})\end{array}$} & \multicolumn{6}{|c|}{ Source Rate ${ }_{10-18}\left(\mu \mathrm{g} \mathrm{h}^{-1}\right)$} & \multirow[b]{2}{*}{$\begin{array}{c}{[\mathrm{C}]_{10-18}} \\
(\mathrm{ppb})\end{array}$} & \multirow[b]{2}{*}{$\mathrm{I} / \mathrm{O}_{10-18}$} \\
\hline & & & & Total & Outdoor & $\begin{array}{l}\text { Recirculated } \\
\text { Room Air }\end{array}$ & $\begin{array}{l}\text { Occupant- } \\
\text { Associated }\end{array}$ & $\begin{array}{l}\text { Indoor } \\
\text { Surfaces }\end{array}$ & $\begin{array}{c}\text { Gas-Phase } \\
\text { Reactions }\end{array}$ & & \\
\hline 14-Feb & $0.10 \pm 0.01$ & $5.3 \pm 2.5$ & $21.8 \pm 2.5$ & $2930 \pm 894$ & $150 \pm 59$ & $146 \pm 38$ & $1880 \pm 890$ & 716 & $38 \pm 10$ & $0.22 \pm 0.08$ & $8.9 \pm 4.4$ \\
\hline 15-Feb & $0.45 \pm 0.02$ & $3.9 \pm 2.3$ & $17.2 \pm 1.7$ & $3121 \pm 717$ & $228 \pm 58$ & $1013 \pm 362$ & $1061 \pm 616$ & 797 & $21 \pm 7$ & $0.22 \pm 0.08$ & $5.2 \pm 2.1$ \\
\hline $18-F e b$ & $0.37 \pm 0.02$ & $3.5 \pm 1.9$ & $17.5 \pm 2.2$ & $3061 \pm 884$ & $99 \pm 34$ & $762 \pm 218$ & $1373 \pm 850$ & 793 & $34 \pm 12$ & $0.22 \pm 0.08$ & $13.9 \pm 5.5$ \\
\hline 26-Feb & $0.26 \pm 0.12$ & $5.6 \pm 2.5$ & $12.7 \pm 1.7$ & $4119 \pm 1360$ & $317 \pm 631$ & $1650 \pm 830$ & $1598 \pm 870$ & 517 & $36 \pm 15$ & $0.26 \pm 0.09$ & $11 \pm 6.1$ \\
\hline 27-Feb & $0.63 \pm 0.06$ & $4.2 \pm 2.7$ & $8.4 \pm 1.5$ & $3246 \pm 760$ & $178 \pm 49$ & $1800 \pm 540$ & $770 \pm 531$ & 474 & $23 \pm 10$ & $0.23 \pm 0.08$ & $6 \pm 1.9$ \\
\hline 28-Feb & $0.66 \pm 0.07$ & $5.3 \pm 2.6$ & $12.9 \pm 1.1$ & $4210 \pm 860$ & $113 \pm 56$ & $2441 \pm 630$ & $1154 \pm 582$ & 461 & $40 \pm 16$ & $0.3 \pm 0.09$ & $12.1 \pm 2.1$ \\
\hline 4-Mar & $0.81 \pm 0.04$ & $3.1 \pm 1.5$ & $14.4 \pm 1.6$ & $3021 \pm 636$ & $47 \pm 16$ & $1898 \pm 467$ & $759 \pm 430$ & 294 & $23 \pm 7$ & $0.19 \pm 0.06$ & $9.8 \pm 4.4$ \\
\hline 5-Mar & $0.77 \pm 0.05$ & $5.2 \pm 2.6$ & $16 \pm 1.5$ & $4820 \pm 1115$ & $89 \pm 20$ & $2566 \pm 647$ & $1695 \pm 906$ & 435 & $35 \pm 12$ & $0.26 \pm 0.08$ & $8.2 \pm 1.7$ \\
\hline 12-Mar & $1.00 \pm 0.00$ & $6.2 \pm 1.9$ & $8.8 \pm 2.8$ & $6386 \pm 1158$ & $0 \pm 0$ & $4956 \pm 1065$ & $969 \pm 452$ & 421 & $37 \pm 13$ & $0.37 \pm 0.09$ & $\mathrm{NaN}$ \\
\hline 14-Mar & $0.00 \pm 0.00$ & $6.2 \pm 2.3$ & $28.7 \pm 4.2$ & $6793 \pm 1960$ & $872 \pm 110$ & $0 \pm 0$ & $3630 \pm 1953$ & 2179 & $111 \pm 35$ & $0.44 \pm 0.12$ & $5.4 \pm 1.3$ \\
\hline 15-Mar & $0.70 \pm 0.02$ & $3.5 \pm 1.6$ & $17.3 \pm 1.6$ & $4582 \pm 803$ & $131 \pm 61$ & $2185 \pm 571$ & $1150 \pm 560$ & 1076 & $39 \pm 11$ & $0.23 \pm 0.06$ & $8 \pm 3.7$ \\
\hline \multicolumn{12}{|l|}{ 4-OPA } \\
\hline 14-Feb & $0.10 \pm 0.01$ & $5.3 \pm 2.5$ & $21.8 \pm 2.5$ & $3034 \pm 371$ & $587 \pm 168$ & $239 \pm 79$ & $591 \pm 319$ & 1086 & $531 \pm 236$ & $0.31 \pm 0.10$ & $3.6 \pm 4.4$ \\
\hline 15-Feb & $0.45 \pm 0.02$ & $3.9 \pm 2.3$ & $17.2 \pm 1.7$ & $2882 \pm 457$ & $248 \pm 67$ & $1214 \pm 387$ & $367 \pm 234$ & 684 & $370 \pm 120$ & $0.26 \pm 0.07$ & $6.4 \pm 2.1$ \\
\hline 18-Feb & $0.37 \pm 0.02$ & $3.5 \pm 1.9$ & $17.5 \pm 2.2$ & $3129 \pm 375$ & $223 \pm 59$ & $1063 \pm 270$ & $377 \pm 234$ & 970 & $495 \pm 163$ & $0.3 \pm 0.08$ & $8.1 \pm 5.5$ \\
\hline 26-Feb & $0.26 \pm 0.12$ & $5.6 \pm 2.5$ & $12.7 \pm 1.7$ & $4119 \pm 1403$ & $610 \pm 910$ & $2209 \pm 1039$ & $439 \pm 239$ & 448 & $413 \pm 173$ & $0.36 \pm 0.11$ & $5.5 \pm 6.1$ \\
\hline 27-Feb & $0.63 \pm 0.06$ & $4.2 \pm 2.7$ & $8.4 \pm 1.5$ & $3715 \pm 465$ & $298 \pm 80$ & $2464 \pm 432$ & $212 \pm 146$ & 490 & $251 \pm 83$ & $0.34 \pm 0.07$ & $5.1 \pm 1.9$ \\
\hline $28-F e b$ & $0.66 \pm 0.07$ & $5.3 \pm 2.6$ & $12.9 \pm 1.1$ & $4664 \pm 735$ & $292 \pm 131$ & $3197 \pm 705$ & $317 \pm 160$ & 488 & $370 \pm 110$ & $0.41 \pm 0.10$ & $6 \pm 2.1$ \\
\hline 4-Mar & $0.81 \pm 0.04$ & $3.1 \pm 1.5$ & $14.4 \pm 1.6$ & $3149 \pm 781$ & $65 \pm 29$ & $2469 \pm 771$ & $209 \pm 118$ & 155 & $252 \pm 80$ & $0.25 \pm 0.08$ & $9.1 \pm 4.4$ \\
\hline 5-Mar & $0.77 \pm 0.05$ & $5.2 \pm 2.6$ & $16 \pm 1.5$ & $4463 \pm 800$ & $139 \pm 65$ & $3104 \pm 755$ & $466 \pm 249$ & 292 & $463 \pm 160$ & $0.34 \pm 0.10$ & $6.8 \pm 1.7$ \\
\hline 12-Mar & $1.00 \pm 0.00$ & $6.2 \pm 1.9$ & $8.8 \pm 2.8$ & $6743 \pm 1377$ & $0 \pm 0$ & $6021 \pm 1371$ & $266 \pm 124$ & 84 & $368 \pm 147$ & $0.55 \pm 0.13$ & $\mathrm{NaN}$ \\
\hline 14-Mar & $0.00 \pm 0.00$ & $6.2 \pm 2.3$ & $28.7 \pm 4.2$ & $5724 \pm 569$ & $881 \pm 132$ & $0 \pm 0$ & $998 \pm 537$ & 2471 & $1373 \pm 392$ & $0.58 \pm 0.09$ & $7.8 \pm 1.3$ \\
\hline 15-Mar & $0.70 \pm 0.02$ & $3.5 \pm 1.6$ & $17.3 \pm 1.6$ & $5927 \pm 671$ & $193 \pm 127$ & $3296 \pm 639$ & $316 \pm 154$ & 1589 & $533 \pm 116$ & $0.39 \pm 0.07$ & $9.4 \pm 3.7$ \\
\hline \multicolumn{12}{|l|}{ Decanal } \\
\hline 14-Feb & $0.10 \pm 0.01$ & $5.3 \pm 2.5$ & $21.8 \pm 2.5$ & $2544 \pm 547$ & $284 \pm 44$ & $166 \pm 35$ & $1148 \pm 544$ & 946 & $\mathrm{NaN}$ & $0.17 \pm 0.03$ & $5.3 \pm 0.4$ \\
\hline 15-Feb & $0.45 \pm 0.02$ & $3.9 \pm 2.3$ & $17.2 \pm 1.7$ & $2974 \pm 433$ & $150 \pm 29$ & $1106 \pm 212$ & $648 \pm 376$ & 1070 & $\mathrm{NaN}$ & $0.17 \pm 0.04$ & $8.4 \pm 1.5$ \\
\hline 18-Feb & $0.37 \pm 0.02$ & $3.5 \pm 1.9$ & $17.5 \pm 2.2$ & $2570 \pm 539$ & $62 \pm 23$ & $617 \pm 130$ & $838 \pm 519$ & 1053 & $\mathrm{NaN}$ & $0.16 \pm 0.03$ & $17 \pm 1.2$ \\
\hline 26-Feb & $0.26 \pm 0.12$ & $5.6 \pm 2.5$ & $12.7 \pm 1.7$ & $3583 \pm 928$ & $299 \pm 473$ & $1618 \pm 593$ & $976 \pm 531$ & 690 & $\mathrm{NaN}$ & $0.21 \pm 0.05$ & $13.8 \pm 0.9$ \\
\hline 27-Feb & $0.63 \pm 0.06$ & $4.2 \pm 2.7$ & $8.4 \pm 1.5$ & $2891 \pm 421$ & $91 \pm 22$ & $1738 \pm 267$ & $470 \pm 324$ & 592 & $\mathrm{NaN}$ & $0.18 \pm 0.04$ & $11.8 \pm 0.7$ \\
\hline 28-Feb & $0.66 \pm 0.07$ & $5.3 \pm 2.6$ & $12.9 \pm 1.1$ & $3764 \pm 561$ & $80 \pm 34$ & $2320 \pm 432$ & $704 \pm 356$ & 659 & $\mathrm{NaN}$ & $0.23 \pm 0.05$ & $16.6 \pm 0.6$ \\
\hline 4-Mar & $0.81 \pm 0.04$ & $3.1 \pm 1.5$ & $14.4 \pm 1.6$ & $2760 \pm 357$ & $17 \pm 7$ & $1836 \pm 241$ & $463 \pm 263$ & 444 & $\mathrm{NaN}$ & $0.15 \pm 0.03$ & $29.2 \pm 3.6$ \\
\hline 5-Mar & $0.77 \pm 0.05$ & $5.2 \pm 2.6$ & $16 \pm 1.5$ & $3691 \pm 665$ & $48 \pm 13$ & $2250 \pm 367$ & $1035 \pm 553$ & 358 & $\mathrm{NaN}$ & $0.19 \pm 0.04$ & $14.1 \pm 0.8$ \\
\hline 12-Mar & $1.00 \pm 0.00$ & $6.2 \pm 1.9$ & $8.8 \pm 2.8$ & $6259 \pm 592$ & $0 \pm 0$ & $5362 \pm 523$ & $592 \pm 276$ & 303 & $\mathrm{NaN}$ & $0.33 \pm 0.04$ & $\mathrm{NaN}$ \\
\hline 14-Mar & $0.00 \pm 0.00$ & $6.2 \pm 2.3$ & $28.7 \pm 4.2$ & $5584 \pm 1197$ & $856 \pm 67$ & $0 \pm 0$ & $2217 \pm 1192$ & 2511 & $\mathrm{NaN}$ & $0.32 \pm 0.05$ & $4.6 \pm 1.1$ \\
\hline 15-Mar & $0.70 \pm 0.02$ & $3.5 \pm 1.6$ & $17.3 \pm 1.6$ & $4709 \pm 487$ & $177 \pm 58$ & $2422 \pm 341$ & $702 \pm 342$ & 1408 & $\mathrm{NaN}$ & $0.22 \pm 0.03$ & $7.3 \pm 2.6$ \\
\hline
\end{tabular}


Table S4. Relative contribution of each source. The unshaded area represents the daily mean values. The shaded area represents the mean values obtained during the high occupancy period (10:00-18:00).

\begin{tabular}{|c|c|c|c|c|c|c|}
\hline 6-MHO & $\begin{array}{c}\text { Outdoor } \\
\text { Air }\end{array}$ & $\begin{array}{c}\text { Recirculated } \\
\text { Room Air }\end{array}$ & $\begin{array}{c}\text { Occupant- } \\
\text { Associated }\end{array}$ & $\begin{array}{c}\text { Indoor } \\
\text { Surfaces }\end{array}$ & $\begin{array}{c}\text { Gas- } \\
\text { Phase } \\
\text { Reactions }\end{array}$ & RR \\
\hline 14-Feb & 0.07 & 0.07 & 0.46 & 0.40 & 0.01 & $0.16 \pm 0.07$ \\
\hline 15-Feb & 0.08 & 0.31 & 0.22 & 0.38 & 0.01 & $0.43 \pm 0.06$ \\
\hline 18-Feb & 0.04 & 0.25 & 0.33 & 0.38 & 0.01 & $0.38 \pm 0.02$ \\
\hline 26-Feb & 0.06 & 0.47 & 0.26 & 0.20 & 0.01 & $0.61 \pm 0.13$ \\
\hline 27-Feb & 0.06 & 0.61 & 0.14 & 0.19 & 0.01 & $0.69 \pm 0.06$ \\
\hline 28-Feb & 0.03 & 0.62 & 0.18 & 0.16 & 0.01 & $0.72 \pm 0.07$ \\
\hline 4-Mar & 0.02 & 0.65 & 0.20 & 0.13 & 0.01 & $0.82 \pm 0.02$ \\
\hline 5-Mar & 0.02 & 0.57 & 0.25 & 0.14 & 0.01 & $0.80 \pm 0.04$ \\
\hline 12-Mar & 0.00 & 0.86 & 0.08 & 0.05 & 0.01 & $1.00 \pm 0.00$ \\
\hline 14-Mar & 0.17 & 0.00 & 0.33 & 0.48 & 0.02 & $0.00 \pm 0.00$ \\
\hline 15-Mar & 0.04 & 0.39 & 0.18 & 0.38 & 0.01 & $0.40 \pm 0.32$ \\
\hline 14-Feb & 0.05 & 0.05 & 0.62 & 0.27 & 0.01 & $0.10 \pm 0.01$ \\
\hline 15-Feb & 0.07 & 0.32 & 0.34 & 0.26 & 0.01 & $0.45 \pm 0.02$ \\
\hline 18-Feb & 0.03 & 0.25 & 0.45 & 0.26 & 0.01 & $0.37 \pm 0.02$ \\
\hline 26-Feb & 0.08 & 0.40 & 0.39 & 0.13 & 0.01 & $0.26 \pm 0.12$ \\
\hline 27-Feb & 0.05 & 0.55 & 0.24 & 0.15 & 0.01 & $0.63 \pm 0.06$ \\
\hline 28-Feb & 0.03 & 0.58 & 0.27 & 0.11 & 0.01 & $0.66 \pm 0.07$ \\
\hline 4-Mar & 0.02 & 0.63 & 0.25 & 0.10 & 0.01 & $0.81 \pm 0.04$ \\
\hline 5-Mar & 0.02 & 0.53 & 0.35 & 0.09 & 0.01 & $0.77 \pm 0.05$ \\
\hline 12-Mar & 0.00 & 0.80 & 0.16 & 0.04 & 0.01 & $1.00 \pm 0.00$ \\
\hline 14-Mar & 0.13 & 0.00 & 0.53 & 0.32 & 0.02 & $0.00 \pm 0.00$ \\
\hline 15-Mar & 0.03 & 0.48 & 0.25 & 0.23 & 0.01 & $0.70 \pm 0.02$ \\
\hline
\end{tabular}




\begin{tabular}{|c|c|c|c|c|c|c|}
\hline 4-OPA & $\begin{array}{c}\text { Outdoor } \\
\text { Air }\end{array}$ & $\begin{array}{c}\text { Recirculated } \\
\text { Room Air }\end{array}$ & $\begin{array}{c}\text { Occupant- } \\
\text { Associated }\end{array}$ & $\begin{array}{c}\text { Indoor } \\
\text { Surfaces }\end{array}$ & $\begin{array}{c}\text { Gas- } \\
\text { Phase } \\
\text { Reactions }\end{array}$ & RR \\
\hline 14-Feb & 0.21 & 0.10 & 0.11 & 0.40 & 0.18 & $0.16 \pm 0.07$ \\
\hline 15-Feb & 0.11 & 0.40 & 0.07 & 0.29 & 0.14 & $0.43 \pm 0.06$ \\
\hline 18-Feb & 0.08 & 0.33 & 0.07 & 0.39 & 0.13 & $0.38 \pm 0.02$ \\
\hline 26-Feb & 0.11 & 0.60 & 0.06 & 0.13 & 0.10 & $0.61 \pm 0.13$ \\
\hline 27-Feb & 0.07 & 0.69 & 0.03 & 0.14 & 0.07 & $0.69 \pm 0.06$ \\
\hline 28-Feb & 0.05 & 0.71 & 0.04 & 0.12 & 0.08 & $0.72 \pm 0.07$ \\
\hline 4-Mar & 0.02 & 0.79 & 0.05 & 0.06 & 0.08 & $0.82 \pm 0.02$ \\
\hline 5-Mar & 0.03 & 0.72 & 0.06 & 0.09 & 0.10 & $0.80 \pm 0.04$ \\
\hline 12-Mar & 0.00 & 0.92 & 0.02 & 0.01 & 0.05 & $1.00 \pm 0.00$ \\
\hline 14-Mar & 0.17 & 0.00 & 0.09 & 0.53 & 0.22 & $0.00 \pm 0.00$ \\
\hline 15-Mar & 0.06 & 0.42 & 0.03 & 0.37 & 0.11 & $0.40 \pm 0.32$ \\
\hline 14-Feb & 0.19 & 0.08 & 0.19 & 0.36 & 0.17 & $0.10 \pm 0.01$ \\
\hline 15-Feb & 0.09 & 0.42 & 0.13 & 0.24 & 0.13 & $0.45 \pm 0.02$ \\
\hline 18-Feb & 0.07 & 0.34 & 0.12 & 0.31 & 0.16 & $0.37 \pm 0.02$ \\
\hline 26-Feb & 0.15 & 0.54 & 0.11 & 0.11 & 0.10 & $0.26 \pm 0.12$ \\
\hline 27-Feb & 0.08 & 0.66 & 0.06 & 0.13 & 0.07 & $0.63 \pm 0.06$ \\
\hline 28-Feb & 0.06 & 0.69 & 0.07 & 0.10 & 0.08 & $0.66 \pm 0.07$ \\
\hline 4-Mar & 0.02 & 0.78 & 0.07 & 0.05 & 0.08 & $0.81 \pm 0.04$ \\
\hline 5-Mar & 0.03 & 0.70 & 0.10 & 0.07 & 0.10 & $0.77 \pm 0.05$ \\
\hline 12-Mar & 0.00 & 0.89 & 0.04 & 0.01 & 0.05 & $1.00 \pm 0.00$ \\
\hline 14-Mar & 0.15 & 0.00 & 0.17 & 0.43 & 0.24 & $0.00 \pm 0.00$ \\
\hline 15-Mar & 0.03 & 0.56 & 0.05 & 0.27 & 0.09 & $0.70 \pm 0.02$ \\
\hline & & & & & & \\
\hline
\end{tabular}




\begin{tabular}{|c|c|c|c|c|c|}
\hline Decanal & $\begin{array}{c}\text { Outdoor } \\
\text { Air }\end{array}$ & $\begin{array}{c}\text { Recirculated } \\
\text { Room Air }\end{array}$ & $\begin{array}{c}\text { Occupant- } \\
\text { Associated }\end{array}$ & $\begin{array}{c}\text { Indoor } \\
\text { Surfaces }\end{array}$ & RR \\
\hline 14-Feb & 0.09 & 0.07 & 0.27 & 0.56 & $0.16 \pm 0.07$ \\
\hline 15-Feb & 0.04 & 0.34 & 0.13 & 0.49 & $0.43 \pm 0.06$ \\
\hline 18-Feb & 0.02 & 0.23 & 0.21 & 0.53 & $0.38 \pm 0.02$ \\
\hline 26-Feb & 0.05 & 0.52 & 0.16 & 0.27 & $0.61 \pm 0.13$ \\
\hline 27-Feb & 0.03 & 0.65 & 0.08 & 0.23 & $0.69 \pm 0.06$ \\
\hline 28-Feb & 0.02 & 0.66 & 0.11 & 0.21 & $0.72 \pm 0.07$ \\
\hline 4-Mar & 0.01 & 0.70 & 0.11 & 0.18 & $0.82 \pm 0.02$ \\
\hline 5-Mar & 0.01 & 0.68 & 0.17 & 0.13 & $0.80 \pm 0.04$ \\
\hline 12-Mar & 0.00 & 0.94 & 0.05 & 0.01 & $1.00 \pm 0.00$ \\
\hline 14-Mar & 0.19 & 0.00 & 0.22 & 0.60 & $0.00 \pm 0.00$ \\
\hline 15-Mar & 0.08 & 0.40 & 0.09 & 0.42 & $0.40 \pm 0.32$ \\
\hline 14-Feb & 0.10 & 0.06 & 0.41 & 0.43 & $0.10 \pm 0.01$ \\
\hline 15-Feb & 0.05 & 0.37 & 0.22 & 0.36 & $0.45 \pm 0.02$ \\
\hline 18-Feb & 0.02 & 0.24 & 0.33 & 0.41 & $0.37 \pm 0.02$ \\
\hline 26-Feb & 0.08 & 0.45 & 0.27 & 0.19 & $0.26 \pm 0.12$ \\
\hline 27-Feb & 0.03 & 0.60 & 0.16 & 0.20 & $0.63 \pm 0.06$ \\
\hline 28-Feb & 0.02 & 0.62 & 0.19 & 0.18 & $0.66 \pm 0.07$ \\
\hline 4-Mar & 0.01 & 0.67 & 0.17 & 0.16 & $0.81 \pm 0.04$ \\
\hline 5-Mar & 0.01 & 0.61 & 0.28 & 0.10 & $0.77 \pm 0.05$ \\
\hline 12-Mar & 0.00 & 0.89 & 0.10 & 0.01 & $1.00 \pm 0.00$ \\
\hline 14-Mar & 0.15 & 0.00 & 0.40 & 0.45 & $0.00 \pm 0.00$ \\
\hline 15-Mar & 0.04 & 0.51 & 0.15 & 0.30 & $0.70 \pm 0.02$ \\
\hline
\end{tabular}




\section{References}

(1) Sadeghi, S. A.; Karava, P.; Konstantzos, I.; Tzempelikos, A. Occupant Interactions with Shading and Lighting Systems Using Different Control Interfaces: A Pilot Field Study. Build. Environ. 2016, 97, 177195.

(2) Kim, J. Characterizing the In-Situ Performance of Passive Chilled Beams. ASHRAE Trans. 2015, 121, $1 \mathrm{~N}$.

(3) Wagner, D. N.; Mathur, A.; Boor, B. E. Spatial Seated Occupancy Detection in Offices with a ChairBased Temperature Sensor Array. Build. Environ. 2021 187, 107360.

(4) Wisthaler, A.; Weschler, C. J. Reactions of Ozone with Human Skin Lipids: Sources of Carbonyls, Dicarbonyls, and Hydroxycarbonyls in Indoor Air. Proc. Natl. Acad. Sci. 2010, 107 (15), 6568-6575.

(5) D’Anna, B.; Wisthaler, A.; Andreasen, Ø.; Hansel, A.; Hjorth, J.; Jensen, N. R.; Nielsen, C. J.; Stenstrøm, Y.; Viidanoja, J. Atmospheric Chemistry of C3-C6 Cycloalkanecarbaldehydes. J. Phys. Chem. A 2005, 109 (23), 5104-5118.

(6) Liu, Y.; Misztal, P. K.; Xiong, J.; Tian, Y.; Arata, C.; Weber, R. J.; Nazaroff, W. W.; Goldstein, A. H. Characterizing Sources and Emissions of Volatile Organic Compounds in a Northern California Residence Using Space-and Time-resolved Measurements. Indoor Air 2019, 29 (4), 630-644.

(7) Tang, X.; Misztal, P. K.; Nazaroff, W. W.; Goldstein, A. H. Volatile Organic Compound Emissions from Humans Indoors. Environ. Sci. Technol. 2016, 50 (23), 12686-12694.

(8) Pagonis, D.; Price, D.; Algrim, L. B.; Day, D. A.; Handschy, A.; Stark, H.; Miller, S. L.; de Gouw, J. A.; Jimenez, J. L.; Ziemann, P. J. Time-Resolved Measurements of Indoor Chemical Emissions, Deposition, and Reactions in a University Art Museum. Environ. Sci. Technol. 2019.

(9) Du Bois, D. A Formula to Estimate the Approximate Surface Area If Height and Weight Be Known. Nutrition 1989, 5, 303-313.

(10) Xiong, J.; He, Z.; Tang, X.; Misztal, P. K.; Goldstein, A. H. Modeling the Time-Dependent Concentrations of Primary and Secondary Reaction Products of Ozone with Squalene in a University Classroom. Environ. Sci. Technol. 2019, 53 (14), 8262-8270. 